\title{
Reference
}

Douglas, D. A. 1991. Clonal architecture of Salix setchelliana (gravel bar willow) in Alaska. Canadian Journal of Botany 69, 590-6.

\section{A chemotaxonomic survey of phenolic compounds in Swiss willow species}

\author{
Beat Meier $^{1,4}$, Y. Shao' ${ }^{1}$ R. Julkunen-Tiitto ${ }^{2}$, A. Bettschart ${ }^{3}$, O. Sticher ${ }^{1}$ \\ ${ }^{1}$ Department of Pharmacy, Swiss Federal Institute of Technology (ETH), Zürich, \\ CH-8092 Zürich \\ ${ }^{2}$ Department of Biology, University of Joensuu, Box 111, SF-80101 Joensuu \\ ${ }^{3}$ Engel-Apotheke, Ch-8840 Einsiedeln \\ ${ }^{4}$ Zeller AG, Herbal Remedies, CH-8490 Romanshorn, Switzerland
}

A phytochemical atlas of all Salix species found in Switzerland has been created (Shao 1991), based on both known (total $=24$ ) and unknown phenolics in the bark and leaves using the HPLC method. The known compounds have been quantitatively analysed while the unknown compounds, so far as possible, have been classified according to the on line UV spectra detected by the diode array system (Meier \& Sticher 1986). A chemotaxonomical classification of the willow species into groups with a high yield of salicin-derivatives showed a homogeneous result for the subgenus Chametia. All species except $S$. herbacea L. are rich ( $>1 \%$ in dried material) in salicortin (2'-O-Acetylsalicortin) in their bark and leaves. $S$. herbacea contains phenolic glycosides only in its bark. The species of the subgenus Amerina can be divided into two groups; one rich in derivatives of salicin ( $2^{\prime}$-O-Acetylsalicin) e.g. $S$. pentandra $\mathrm{L}$. and $S$. fragilis $\mathrm{L}$., and the other poor in these compounds e.g. $S$. alba L., $S$. triandra L. Until now, high amounts of acetylates of salicin and salicortin have been detected only in the species of this subgenus. The subgenus Caprisalix could also be divided into the same two groups. The main salicin derivatives are tremulacin and salicortin.

The cluster analyses showed only small differences between pairs within the species of the section Caprea (S. caprea L., S. cinerea L., S. aurita L., S. appendiculata Vill., $S$. laggeri Wimmer) in leaves and their barks. Capreae is the most homogeneous section of the subgenus Caprisalix and belongs to the group poor in salicin derivatives. The main phenolic glycoside in the bark of all species is triandrin.

Similar to earlier results, the new data shows a fairly constant spectra of phenolic compounds, at least the phenolic glycosides, within a species. This leads to the possibility to confirm hybrid forms with a phytochemical analysis. Hybrids of $S$. hastata $\times$ waldsteiniana have been detected with this technique (Meier et al. 1989). The hypothesis of Lautenschlager to declare $S$. hegetschweileri Heer. as a hybrid of $S$. bicolor Ehrh. and $S$. nigricans ssp. alpicola Buser was confirmed by comparing the HPLC-chromatograms of the leaves of all three species. No differences were detected in their barks. Other than for Finnish and Swiss willows there is a general lack of information for world-wide willow species. Will chemotaxonomy be a useful tool for the classification of willows? Only time will tell, but techniques already exist which obtain valid results by GC and HPLC (Meier et al. 1988; Julkunen-Tiitto 

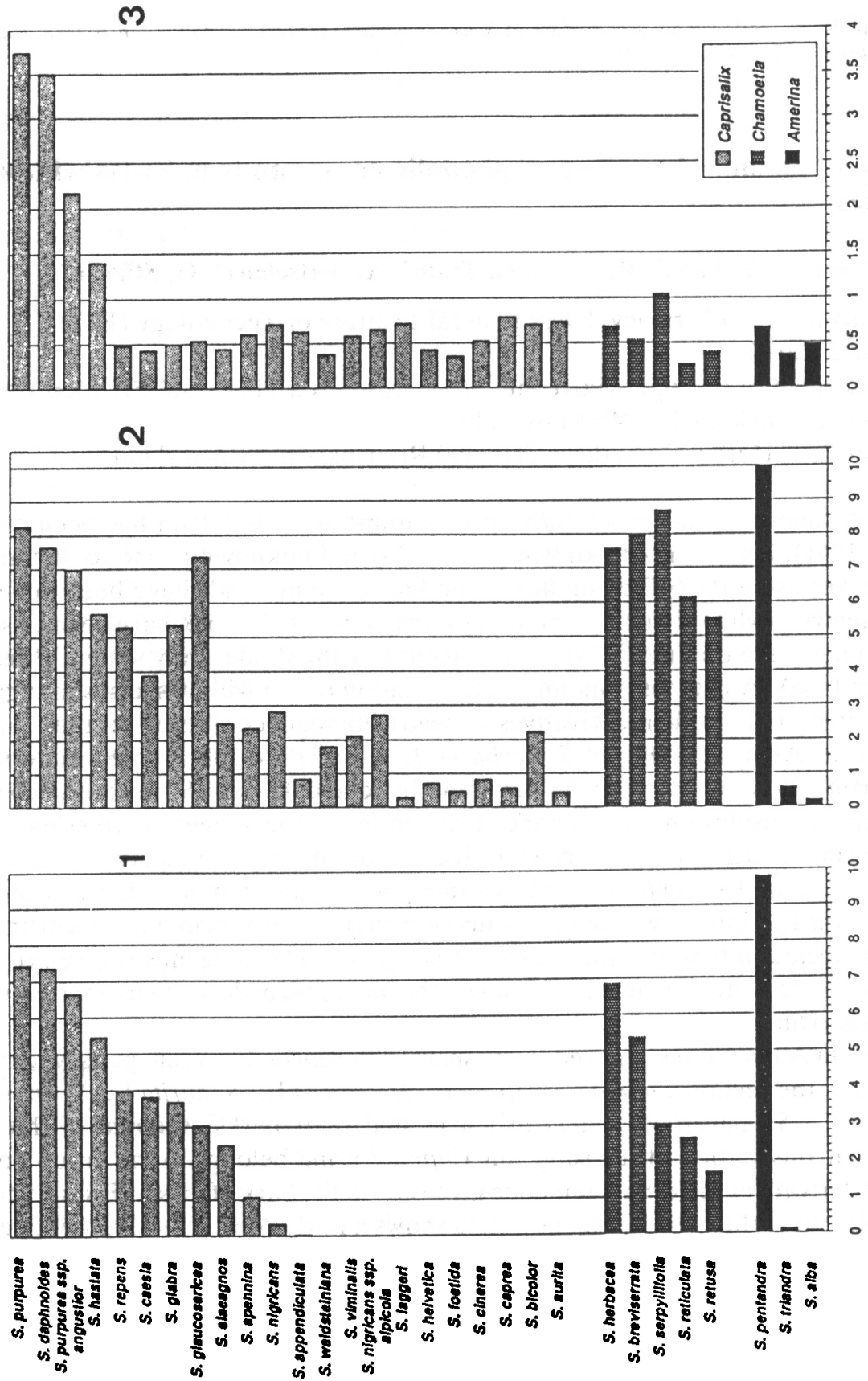

Figure 1. Distribution of phenolic compounds in the bark of Swiss willow species. (1) Total amount of salicin derivatives; (2) total amount of phenolic glycosides; (3) total amount of flavonoides (all in \% per dry weight). 

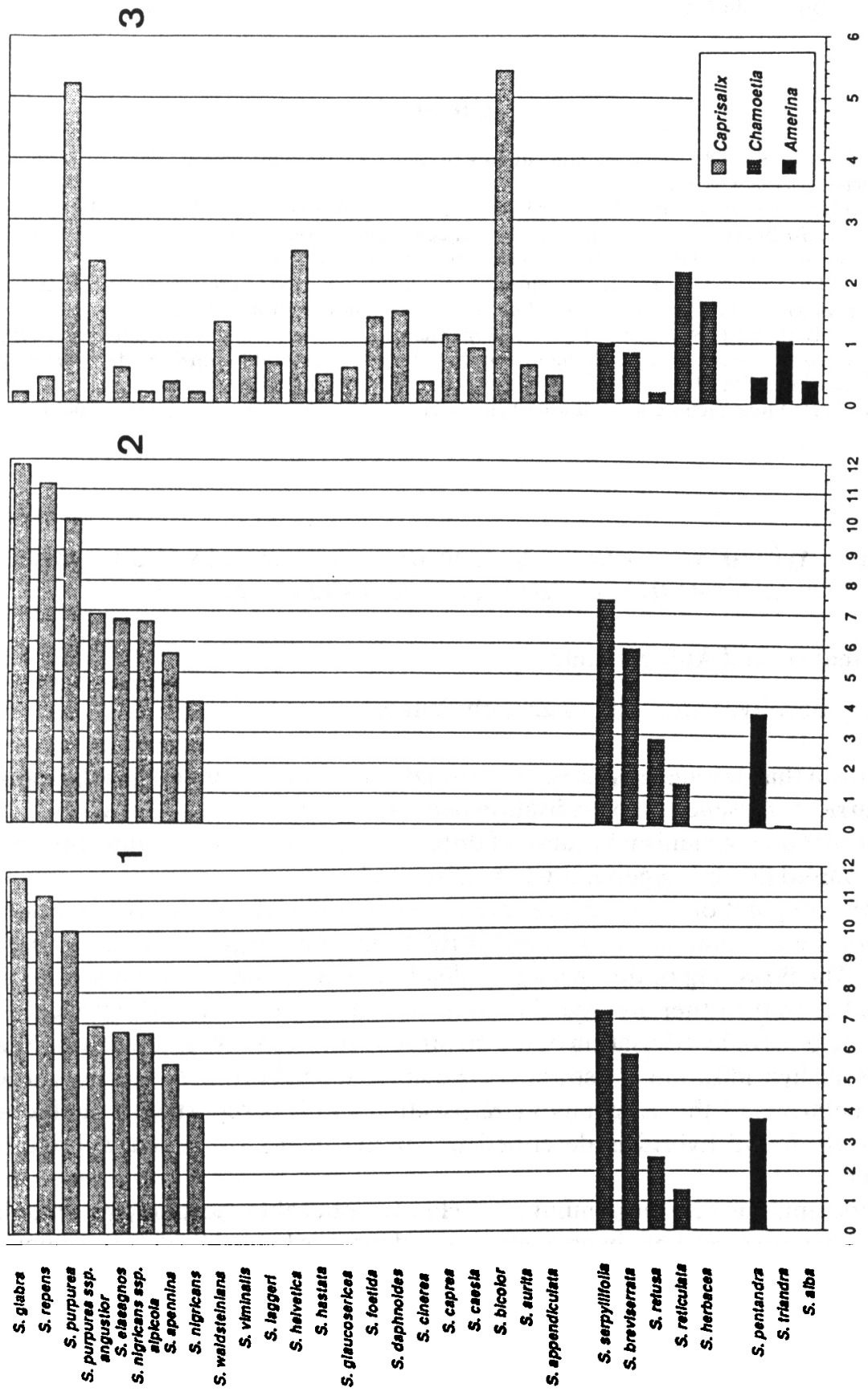

Figure 2. Distribution of phenolic compounds in the leaves of Swiss willow species. (1) Total amount of salicin derivatives; (2) Total amount of phenolic glycosides; (3) Total amount of flavonoides (all in \% per dry weight). 
1989). Until now, the chemical composition appears to be only partly consistent with morphological classification.

\section{References}

Julkunen-Tiitto, R. 1989. Phenolic constituents of Salix: a chemotaxonomic survey of further finnish species. Phytochem 28, 2115.

Lautenschlager-Fleury, D. and E.: Zur Abklärung der Salix hegetschweileri Heer. Bauhinia (in press).

Meier, B. \& Sticher, O. 1986. The use of a high speed spectrophotometric detector (diode-array) in the HPLC-analysis of medicinal plants. Pharmazeutische Industrie 48, 87.

Meier, B., Julkunen-Tiitto, R., Tahvanainen, J. \& Sticher, O. 1988. Comparable HPLC and GLC of phenolic glucosides of Salix species. Journal of Chromatography 442, 175.

Meier, B., Bettschart, A., Shao, Y. \& Lautenschlager, E. 1989. Einsatz der modernen HPLC für chemotaxonomische Untersuchungen morphologisch schwer zu differenzierender Salix-Hybriden. Planta medica 55, 213.

Shao, Y. 1991. Phytochemischer Atlas der Schweizer Weiden. Thesis No. 9532, ETH Zürich.

\section{Natural hybrid Salix alba $\times S$. fragilis $\times S$. caprea $(S . \times$ savensis Trinajstić et Krstinić) - inheritance of some characters}

\section{Ivo Trinajstić and Ante Krstinić}

Forestry Faculty, University of Zagreb, Yugoslavia

It is known that among most species of the genus Salix there are no genetic reproductive barriers. Absence of hybridisation between various species is most often caused by an isolation mechanism because of differences in the flowering time. Species with synchronised flowering generally hybridise easily.

In the populations of various species of willows along the River Sava near Zagreb, the spontaneous trispecies hybrid $S$ alba $\times S$. fragilis $\times S$. caprea has been found. The flowering of the species $S$. alba L. and $S$. fragilis L., on one side, and $S$. caprea $\mathrm{L}$., on the other are asynchronous, with a significant time difference. Therefore the causes of hybridisation of the mentioned species are unknown to us. Since no case of the hybridisation of a species of the subgenus Salix from the section Salix with representatives of the subgenus Vetrix: section Vetrix is reported in the literature, this newly found hybrid is described under the name $S . \times$ savensis Trinajstic et Krstinić.

By the analysis of a large number of clearly noticeable morphologic and physiologic characteristics, it has been demonstrated that the hybrid $S . \times$ savensis unites the properties of three species: $S$. alba, $S$. fragilis and $S$. caprea.

From both $S$. alba and $S$. fragilis, the hybrid inherited the capability of rooting, from $S$. alba the red colour and tough branchlets and from $S$. fragilis the shape of buds and morphology of lateral, summer branchlets. From $S$. caprea an early flowering (pre-leafing), one nectary, pilosity of filaments, bracts, shoots and leaves have been inherited. Some properties such as leaf shape, dentate leaf blade are intermediary.

Under the experimental conditions of rooting, shoots of $S . \times$ savensis first developed branchlets and then roots, whilst the control $S$. caprea simultaneously 